\title{
Kinetics and Mechanism of Oxidation of Glutathione reduced (GSH) and L-cysteine (L-cyst) by aqueous solution of piperidinium chloro chromate: A comparative study
}

\author{
B.Dash, A.K. Patnaik*, G.C. Dash, P. Mohanty* \\ Utkal University, Vani Vihar, Bhubaneswar, Odisha
}

\begin{abstract}
The oxidation reaction of Glutathione reduced (GSH) and L-cysteine (L-cyst) has been studied spectrophotometrically over the range $4.6 \leq 10^{3}$ [substrate] $\leq 13.8$ (when substrate $=$ GSH or L-cysteine), 0.03

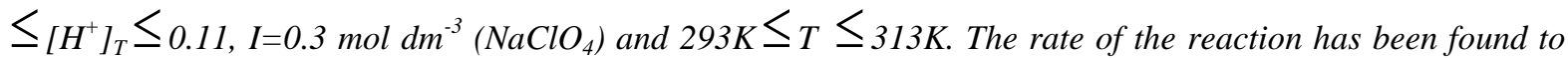
increase with the increase in [Substrate $]_{T}$ and $\left[\mathrm{H}^{+}\right]_{T}$. The reaction follows first order kinetics in [Substrate $]_{T}$ and $[P i p c c]_{T}$. The reaction follows second order kinetics with respect to $\left[\mathrm{H}^{+}\right]_{T}$. The reaction proceeds in two paths $k_{1}$ and $k_{2}$ where $k_{1}$ is acid independent path and $k_{2}$ is acid dependent path,both $k_{1}$ and $k_{2}$ were found to increase with the increase in temperature.

For L-cysteine and GSH, the $\Delta H^{\neq}\left(\mathrm{kJ} \mathrm{mol}^{-1}\right)$ for $k_{1}\left(\mathrm{sec}^{-1}\right)$ paths were found to be $43.8+3.7,27.05+1.3$ and

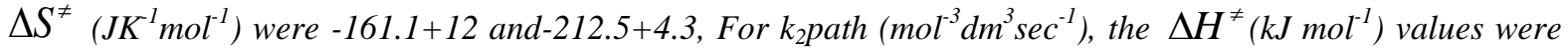
$53.3+3.4$ and $67.5+12.3$ and $\Delta S^{\neq}\left(\mathrm{JK}^{-1} \mathrm{~mol}^{-1}\right)$ values were $-182.6+11$ and $4.6+40$.
\end{abstract}

Negative value of $\Delta S^{\neq}$indicates the reaction passes through a ordered transition state. The oxidation product of L-cysteine and GSH (reduced) are identified as L-cystine and GSSG respectively.

Keywords: GSH, L-cysteine, spectrophotometry, kinetics, product, analysis, cystine and GSSG., activation parameters.

\section{Introduction}

A variety of mild and selective oxidising chromium (VI) reagents like pyridinium chloro chromate, pyridiniumbromo chromate, 2, 2-bipyridinium chloro chromate, imidazolium chloro chromate, quinoliniumfluorochromate, quinoliuium dichromate and isoquinolinium chloro chromate have been used widely in synthetic organic chemistry.1-9 In view of the increasing importance of these chromium (VI) reagents as potential and selective oxidings agents an attempt has been made to extend the study to other halochromates. This paper presents detail kinetics studies and mechanism of oxidation of GSH and L-cysteine by piperidinium chlorochromate10 in perchloric acid medium.

\section{a) Method And Material}

\section{Experimental}

The reactant complex, piperidinium chloro chromate (Pipcc), was prepared and characterized according to the reported method. All other chemicals used were of Analar grade. Doubly distilled water was used to prepare the solutions. The $\mathrm{pH}$ of the solution was adjusted by adding $\mathrm{NaOH} / \mathrm{HCIO}_{4}$ and the $\mathrm{pH}$ measurements were carried out with the help of a prestandardised Elico (India) digital pH meter equipped with glass electrode with an accuracy of $\pm 0.01 \mathrm{pH}$ unit. During kinetic investigation, a constant ionic strength $\left(0.3 \mathrm{~mol} \mathrm{dm}^{-}\right.$ ${ }^{3} \mathrm{NaCIO}_{4}$ ) was maintained.

On mixing L-cysteine with Pipcc solution, there is decrease of absorbance at $\lambda_{\max }=350 \mathrm{~nm}$ and at $\lambda$ $\max =424 \mathrm{~nm}$ (Fig. 2a). Similar plot is obtained for GSH (Fig. 2b)The change in absorbance of the mixture at different time intervals is shown in (Fig. 2b). The reaction progress was monotored at $\lambda_{\max }=424 \mathrm{~nm}$ as there was significant decrease of absorbance.

\section{b) Kinetic Studies}

Kinetic measurements were carried out with a CECIL 7200 UV-VIS (UK) spectrophotometer equipped with a peltier system, temperature control (accuracy $= \pm 0.1^{0} \mathrm{C}$ ). The progress of the reaction was monitored by following the decrease in absorbance at $\lambda_{\max }=424 \mathrm{~nm}$. The conventional mixing technique was followed and 
pseudo-first order conditions were maintained throughout the course of the reaction. The reactionwas followed up to not less than $90 \%$ completion. The reaction mixture was homogeneous in solvent composition and pipcc remained stable over the period of kinetic investigation. The pseuso-first order rate constants $\left(\mathrm{k}_{\mathrm{obs}}\right)$ were calculated from the slopes of $\ln \left(\mathrm{A}_{\mathrm{t}}-\mathrm{A}_{\infty}\right)$ versus time plot, following equation-1.

$$
\text { In }\left(A_{t}-A_{\infty}\right)=C+t \times k_{\text {obs }}
$$

Where, $A_{t}$ and $A_{\infty}$ are the absorbance's of the reaction mixture at time $t$ and at equilibrium respectively.

Rate data represented as an average of duplicate runs are reproducible within $\pm 3 \%$. The correlation coefficient of plots used to determine $\mathrm{k}_{\mathrm{obs}}$ were found to be 0.99 in most of the cases.

\section{C) Stoichiometry And Identification Of Product}

The reaction mixture containing Pipcc and Cysteine or GSH in a molar ratio $1: 10$ was warmed at $313 \mathrm{~K}$ to complete the reaction. The unreacted $\mathrm{Cr}(\mathrm{VI})$ and the product $\mathrm{Cr}(\mathrm{III})$ were estimated form the reported experiment [Vogel, A. I (1989).Text Book of Quantitative Analysis( $5^{\text {th }}$ edition), ELBS, Longman group, UK]. It was observed that 2 moles of Pipcc reacted with 6- moles ofL-cysteine or GSH to generate 2 moles of Cr(III) and 3 moles of cysteine or 3 moles of GSSGrespectively.

$2 \mathrm{Cr}(\mathrm{VI})+6$ Cystine $\rightarrow 2 \mathrm{Cr}(\mathrm{III})+3 \mathrm{Cystin}+6 \mathrm{H}^{+}$

$2 \mathrm{Cr}(\mathrm{VI})+6 \mathrm{GSH} \rightarrow 2 \mathrm{Cr}(\mathrm{III})+3 \mathrm{GSSG}+6 \mathrm{H}^{+}$

In order to get the reaction product, 0.2 moles of Pipcc, and 0.02 moles of cysteine or GSH were mixed at $\left[\mathrm{H}^{+}\right]=0.2 \mathrm{~mol} / \mathrm{dm}^{3}$. The volume of solution was made $50 \mathrm{ml}$. The reaction mixture was warmed for quick completion of the reaction. The reaction mixture was evaporated slowly to get the product. The product was washed with diethylether and was dried in a desiccator. The FTIR of the cysteine and its oxidation product, cysteine are shown in (fig. 1(a) and 1(b)). The FTIR of GSH and its oxidation product, GSSG are shown in fig. $1(\mathrm{c})$ and $1(\mathrm{~d})$.

Fig. 1(b), FTIR spectra of the oxidation product of L-cysteine shows a broad strong peak at $3565 \mathrm{~cm}^{-1}$ in the product which is due to $\mathrm{N}-\mathrm{H}$ stretching as compared to $3179 \mathrm{~cm}^{-1}$ in L-cystine. The shifting to higher frequency is probably due to association of water molecules with the product. The carboxylate group in the product shifted from $1587 \mathrm{~cm}^{-1} 1$ to $1641 \mathrm{~cm}^{-1}$, weak band at $2552 \mathrm{~cm}^{-1}$ in cysteine which is due to S-H stretching is absent in the product. Suggesting that the reactant aminoacid, cysteine, dimerises to disulfanylpropanoic (cystine) having S-S linkage.

Fig.1(d), shows a broad peak at $3397 \mathrm{~cm}^{-1}$ in the product may be assigned to $\mathrm{N}-\mathrm{H}$ stretching as compared to $3252 \mathrm{~cm}^{-1}$ in GSH (fig.1.c). The shifting to higher frequency is probably due to an association of water molecules with the product. The bending bands and a strong absorption peak of carboxylate ion are overlapped forming a broad band at $1651 \mathrm{~cm}^{-1}$ in the product due to carbvoxylate group compared to $1600 \mathrm{~cm}^{-1}$, $1538 \mathrm{~cm}^{-1} \& 1395 \mathrm{~cm}^{-1}$ peak in GSH. The weak band at $2526 \mathrm{~cm}^{-1}$ in GSH due to S-H stretching is absent in the product suggesting the dimerization of GSH to GSSG having S-S linkage.

The structure of cysteine, GSH and their respective products, cystine\& GSSG are shown as :<smiles>CN(N)C(SS)C(=O)O[Hg]</smiles><smiles>CC(C)C(=O)NCC(=O)NC(CSSCC(NC(=O)CCC(N)C(=O)O)C(=O)NCC(=O)O)C(=O)NCC(=O)O</smiles> 


\section{Result And Discussion}

The kinetics of oxidation of glutathione reduced (GSH) and L-cysteine (L-cyst) by aqueous solution of piperidiniumchlorochromate (Pipcc) have been studied. The data are consistent with the rate law.

$\frac{-\mathrm{d}[\text { Pipcc }]}{\mathrm{dt}}=\mathrm{k}_{1}+\mathrm{k}_{2}\left[\mathrm{H}^{+}\right]^{2}$ [Substrate]

The linearity of the pseudo-first order plots implies that the reaction is first order in [Pipcc], values of pseudo-first order rate constant $\left(\mathrm{k}_{\mathrm{obs}}\right)$ obtained at different [Substrate] at a given $\left[\mathrm{H}^{+}\right]$and at a particular temperature are collected in Table (1 and 4). Plot of $\mathrm{k}_{\mathrm{obs}}$ as a function of [Substrate] at a given $\left[\mathrm{H}^{+}\right]$and at constant temperature is linear with a common positive intercept (Fig. 3)

\section{Dependence of Rate on Substrate Concentration}

At $30^{0} \mathrm{C}$ when $[\mathrm{Pipcc}]_{\mathrm{T}}=4.6 \times 10^{-4} \mathrm{~mol} \mathrm{dm}^{-3}, \mathrm{I}=0.3 \mathrm{~mol} \mathrm{dm}^{-3}, 10^{3}[\mathrm{GSH}]$ was varied from 4.6 to 13.8 . The values of $10^{4} \mathrm{k}_{\text {obs }}$ increased from 10.88 to 29.1 , when $\left[\mathrm{H}^{+}\right]=0.01 \mathrm{moldm}^{-3}$. At the same temperature and under the similar conditions, when $10^{3}$ [L-cysteine] was varied from 4.6 to $13.8,10^{4} \mathrm{k}_{\text {obs }}$ increased from 8.07 to 18.48 indicating the fact that $\mathrm{GSH}$, a tripeptide is reacting faster than L-cysteine.

\section{Acid dependence for GSH and L-cysteine}

Keeping all conditions constant, $\left[\mathrm{H}^{+}\right]$was varried. $10^{4}[\mathrm{pipcc}]_{\mathrm{T}}=4.6,10^{3}[\mathrm{GSH}]_{\mathrm{T}}=2.4, \mathrm{I}=0.3 \mathrm{M}$, temperature $=30^{0} \mathrm{C},\left[\mathrm{H}^{+}\right]$was varied from 0.03 to $0.11 \mathrm{~mol} \mathrm{dm}^{-3}, 10^{4} \mathrm{k}_{\text {obs }}$ increased from 11.45 to 18.95 . Under the same condition, when $\left[\mathrm{H}^{+}\right]$was varied from 0.03 to $0.11 \mathrm{~mol} \mathrm{dm}^{-3}, 10^{4} \mathrm{k}_{\mathrm{obs}}$ increased from 6.72 to 10.22 for $\mathrm{L}$ cysteine.

With increasing $\left[\mathrm{H}^{+}\right]$, observed pseudo first order rate constant is found to increase for both L-cysteine and GSH. This indicates that protonated form of the oxidant is taking part in the electron transfer reaction. With the incrasing $\left[\mathrm{H}^{+}\right]$, the concentration of the protonated form of oxidant increases. As a result, the reaction becomes faster.

\section{Temperature dependence for the reaction between Pipcc and the substrate}

When $10^{4}[\text { pipcc }]_{\mathrm{T}}=4.6 \mathrm{~mol} \mathrm{dm}^{-3}, 10^{3}[\mathrm{GSH}]=2.4, \mathrm{I}=0.3 \mathrm{~mol} \mathrm{dm}^{-3}$ and $\left[\mathrm{H}^{+}\right]=0.3 \mathrm{~mol} \mathrm{dm}^{-3}, 10^{4} \mathrm{k}_{\mathrm{obs}}$ changes from 7.5 to 16.94 by increasing the temperature from $20^{\circ} \mathrm{C}$ to $40^{\circ} \mathrm{C}$. Under the same condition for Lcysteine, $10^{4} \mathrm{k}_{\text {obs }}$ changed from 1.97 to 11.4. Similarly increases in temperature, $\mathrm{k}_{\mathrm{obs}}$ increases for both Glutathione reduced and also for L-cysteine. Increase in $\mathrm{k}_{\mathrm{obs}}$ can be explained on the basis of Arrhenius equation. as scheme-1.

Basing on stoichiometry and identification of the product, the probable mechanism may be delineated

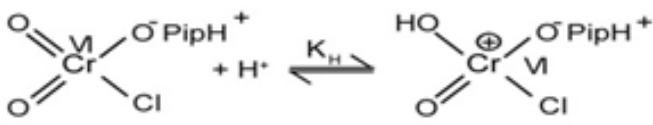

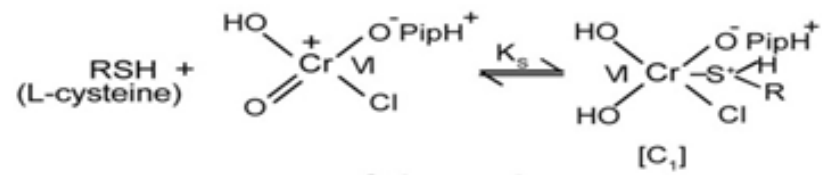

Scheme - -

$\left[\mathrm{C}_{1}\right]$

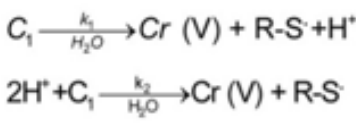

Where $k_{1}$ and $k_{2}$ are acid independent and acid dependent paths of electron transfer rections respectively. Rapid and kinetically unimportant steps of the product formation may probably be visualised as follows.

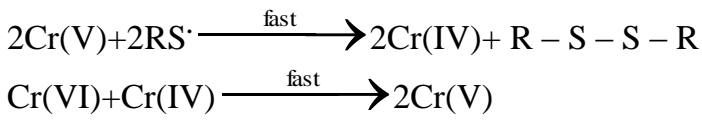


$\mathrm{Cr}(\mathrm{V})+2 \mathrm{RSH} \longrightarrow$ fast $\longrightarrow \mathrm{Cr}(\mathrm{III})+\mathrm{R}-\mathrm{S}-\mathrm{S}-\mathrm{R}+2 \mathrm{H}^{+}$

$\mathrm{Cr}(\mathrm{III})$ is the $\mathrm{Cr}\left(\mathrm{H}_{2} \mathrm{O}\right)_{6}{ }^{3+}$ species in aqueous acidic medium.

(RSH may be L-Cysteine or GSH reduced)

The rate law corresponding to above mechanism is indicated below

Rate $=\frac{-d[\text { Pipcc }]}{d t}=\frac{K[R S H]\left(k_{1}+k_{2}[R S H]\left[H^{+}\right]^{2}[P i p c c]_{T}\right.}{1+K[R S H]}$

$-\frac{\mathrm{d}[\text { Pippc }]}{\mathrm{dt}}=\mathrm{k}_{\mathrm{obs}}[\text { Pipcc }]_{\mathrm{T}}$

Hence

$$
\mathrm{k}_{\mathrm{obs}}=\frac{K[R S H]\left(k_{1}+k_{2}[R S H]\left[H^{+}\right]^{2}\right)}{1+K[R S H]}
$$

If $\mathrm{K}[\mathrm{RSH}]>>1$, equation (5) becomes

Similarly for GSH

$$
\mathrm{k}_{\mathrm{obs}}=\left(\mathrm{k}_{1}+\mathrm{k}_{2} \text { [cysteine] }\right)\left[\mathrm{H}^{+}\right]^{2}
$$

$$
\mathrm{k}_{\mathrm{obs}}=\left(\mathrm{k}_{1}+\mathrm{k}_{2}[\mathrm{GSH}]\right)\left[\mathrm{H}^{+}\right]^{2}
$$

$\mathrm{k}_{\mathrm{obs}} \mathrm{Vs}\left[\mathrm{H}^{+}\right]^{2}$ plot is linear (figure- 4 and 5) for both GSH and L-cysteine is indicating the fact that the rate law is consistent with the mechanism. The values of $\mathrm{k}_{1}$ and $\mathrm{k}_{2}$ were calculated from the intercept and slope. The values are collected in Table 3 and 6.

The oxidation products for L-cysteine and GSH are L-cystine and GSSG respectively. Activation parameters for path $k_{1}$ and $k_{2}$ for both the reactants are collected in Table 3 and 6 . Negativevalue of $\Delta s^{*}$ for both the reactions indicate that the reaction passes through ordered transition states.

Table - 1:Pseudo-first order rate constantfor the oxidation of Pipcc with L-cysteine at different concentrations of L-cysteine.

Variation of concentration of L-cysteine

$\lambda_{\max }=424 \mathrm{~nm},[$ Pipcc $]=4.6 \times 10^{-4} \mathrm{~mol} \mathrm{dm}^{-3},\left[\mathrm{H}^{+}\right]=0.01 \mathrm{~mol} \mathrm{dm}^{-3}$

$\mathrm{I}=0.3 \mathrm{~mol} \mathrm{dm}^{-3}$, temp $=30^{\circ} \mathrm{C}$

\begin{tabular}{|l|l|l|}
\hline $10^{3}[\mathrm{~L}$-cysteine $] \mathrm{mol} \mathrm{dm}^{-3}$ & $10^{4} \mathrm{k}_{\mathrm{obs}}\left(\mathrm{sec}^{-1}\right)$ & $\mathrm{k}_{2}=\left(\frac{\mathrm{k}_{\mathrm{obs}}}{[\mathrm{L}-\mathrm{cyst}]}\right)$ \\
\hline 4.6 & & 0.176 \\
\hline 7.0 & 8.07 & 0.147 \\
\hline 9.2 & 10.27 & 0.133 \\
\hline 11.6 & 12.27 & 0.152 \\
\hline 13.8 & 17.65 & 0.134 \\
\hline
\end{tabular}

Table - 2: Variation of $10^{4} \mathrm{k}_{\mathrm{obs}}$ at different temps and at different $\left[\mathrm{H}^{+}\right]$for reaction of Pipcc with L-cysteine, $=2.4 \times 10^{-3} \mathrm{~mol} \mathrm{dm}^{-3}$ $[\mathrm{Pipcc}]=4.6 \times 10^{-4} \mathrm{~mol} \mathrm{dm}^{-3}, \mathrm{I}=0.3 \mathrm{~mol} \mathrm{dm}^{-3}\left(\mathrm{NaClO}_{4}\right)$, (L-cysteine)

\begin{tabular}{|l|l|l|l|l|l|}
\hline$\left[\mathrm{H}^{+}\right] \mathrm{mol} \mathrm{dm}^{-3}$ & $20^{0} \mathrm{C}$ & $25^{0} \mathrm{C}$ & $30^{0} \mathrm{C}$ & $35^{0} \mathrm{C}$ & $40^{0} \mathrm{C}$ \\
\hline 0.03 & 1.97 & 3.47 & 6.72 & 8.38 & 11.4 \\
\hline 0.05 & 2.30 & 4.01 & 7.50 & 9.95 & 14.08 \\
\hline 0.07 & 3.33 & 5.30 & 8.67 & 11.89 & 16.72 \\
\hline 0.09 & 4.10 & 6.22 & 9.70 & 12.73 & 17.28 \\
\hline 0.11 & 4.50 & 6.76 & 10.22 & 14.03 & 19.42 \\
\hline
\end{tabular}

Table - 3:Electron transfer rate constants $\mathrm{k}_{1}$ and $\mathrm{k}_{2}$ for oxidation of L-cysteine by Pipcc atdifferent temperatures.

\begin{tabular}{|l|l|l|}
\hline Temperature $\left({ }^{0} \mathrm{C}\right)$ & $10^{4} \mathrm{k}_{1}\left(\mathrm{Sec}^{-1}\right)$ & $\mathrm{k}_{2}\left(\mathrm{~mol}^{-3} \mathrm{dm}^{3} \mathrm{sec}^{-1}\right)$ \\
\hline 25 & 5.0 & 9.41 \\
\hline 30 & 7.0 & 13.16 \\
\hline 35 & 9.0 & 20.12 \\
\hline 40 & 12.0 & 27.16 \\
\hline For $\mathrm{k}_{1}$ path & For $\mathrm{k}_{2}$ path \\
\hline
\end{tabular}


Kinetics and Mechanism of Oxidation of Glutathione reduced (GSH) and L-cysteine (L-cyst) by..

\begin{tabular}{|l|l|}
\hline$\Delta \mathrm{H}_{1}^{\neq}=43.8 \pm .3 .7 \mathrm{~kJ} \mathrm{~mol}^{-1}$ & $\Delta \mathrm{H}_{2}^{\neq}=53.3 \pm 3.4 \mathrm{~kJ} \mathrm{~mol}^{-1}$ \\
$\Delta \mathrm{S}_{1}^{\neq}=-161.1 \pm 12 \mathrm{JK}^{-1} \mathrm{~mol}^{-1}$ & $\Delta \mathrm{S}_{2}^{\neq}=-182.6 \pm 11 \mathrm{JK}^{-1} \mathrm{~mol}^{-1}$ \\
\hline
\end{tabular}

Table - 4:Reaction of Pipcc with GSH Pseudo-first order constant with variation of concentration of GSH $\lambda_{\max }=435 \mathrm{~nm},[\mathrm{Pipcc}]=4.6 \times 10^{-4} \mathrm{~mol} \mathrm{dm}^{-3},\left[\mathrm{H}^{+}\right]=0.01 \mathrm{~mol} \mathrm{dm}^{-3}$

$\mathrm{I}=0.3 \mathrm{~mol} \mathrm{dm}^{-3}\left(\mathrm{NaClO}_{4}\right)$, temp $=30^{\circ} \mathrm{C}$

\begin{tabular}{|l|l|l|}
\hline $10^{3}[\mathrm{GSH}] \mathrm{mol} \mathrm{dm}^{-3}$ & $10^{4} \mathrm{kobs}_{\left(\mathrm{sec}^{-1}\right)}$ & $\mathrm{k}_{2}=\left(\frac{\mathrm{k}_{\mathrm{obs}}}{[\mathrm{GSH}]}\right)$ \\
\hline 4.6 & & 0.236 \\
\hline 7.0 & 10.88 & 0.215 \\
\hline 9.2 & 15.03 & 0.230 \\
\hline 11.6 & 21.08 & 0.219 \\
\hline 13.8 & 25.38 & 0.211 \\
\hline
\end{tabular}

Table - 5:Variation of $10^{4} \mathrm{k}_{\text {obs }}$ at different temps and at different $\left[\mathrm{H}^{+}\right]$for reaction of Pipcc with GSH. [Pipcc] = $4.6 \times 10^{-4} \mathrm{~mol} \mathrm{dm}^{-}{ }^{3},[\mathrm{GSH}]=2.4 \times 10^{-3} \mathrm{~mol} \mathrm{dm}^{-3}, \mathrm{I}=0.3 \mathrm{~mol} \mathrm{dm}^{-3}\left(\mathrm{NaClO}_{4}\right), \lambda_{\max }=435 \mathrm{~nm}$

\begin{tabular}{|l|l|l|l|l|l|}
\hline$\left[\mathrm{H}^{+}\right] \mathrm{mol} \mathrm{dm}^{-3}$ & $20^{0} \mathrm{C}$ & $25^{0} \mathrm{C}$ & $30^{\circ} \mathrm{C}$ & $35^{\circ} \mathrm{C}$ & $40^{0} \mathrm{C}$ \\
\hline 0.03 & 7.50 & 9.31 & 11.45 & 13.90 & 16.94 \\
\hline 0.05 & 7.87 & 9.93 & 12.62 & 14.93 & 18.62 \\
\hline 0.07 & 8.17 & 11.07 & 15.63 & 17.72 & 24.10 \\
\hline 0.09 & 8.80 & 12.16 & 17.25 & 20.92 & 28.71 \\
\hline 0.11 & 9.35 & 13.15 & 18.95 & 23.38 & 32.58 \\
\hline
\end{tabular}

Table - 6: Electron transfer rate constants $\mathrm{k}_{1}$ and $\mathrm{k}_{2}$ for oxidation of GSH by Pipcc at different temperatures.

\begin{tabular}{|l|l|l|}
\hline Temperature $\left({ }^{0} \mathrm{C}\right)$ & $10^{4} \mathrm{k}_{1}\left(\mathrm{Sec}^{-1}\right)$ & $\mathrm{k}_{2}\left(\mathrm{~mol}^{-3} \mathrm{dm}^{3} \mathrm{sec}^{-1}\right)$ \\
\hline 25 & 9.0 & 14.50 \\
\hline 30 & 11.0 & 28.33 \\
\hline 35 & 13.0 & 36.79 \\
\hline 40 & 16.0 & 60.58 \\
\hline For $\mathrm{k}_{1}$ path & & For k $\mathrm{path}^{-1}$ \\
$\Delta \mathrm{H}_{1}^{\neq}=27.05 \pm .1 .3 \mathrm{~kJ} \mathrm{~mol}^{-1}$ & $\Delta \mathrm{H}_{2}^{\neq}=67.5 \pm 12.3 \mathrm{~kJ} \mathrm{~mol}^{-1}$ \\
$\Delta \mathrm{S}_{1}^{ \pm}=-212.5 \pm 4.3 \mathrm{JK}^{-1} \mathrm{~mol}^{-1}$ & & $\Delta \mathrm{S}_{2}^{ \pm}=4.6 \pm 40 \mathrm{JK}^{-1} \mathrm{~mol}^{-1}$ \\
\hline
\end{tabular}

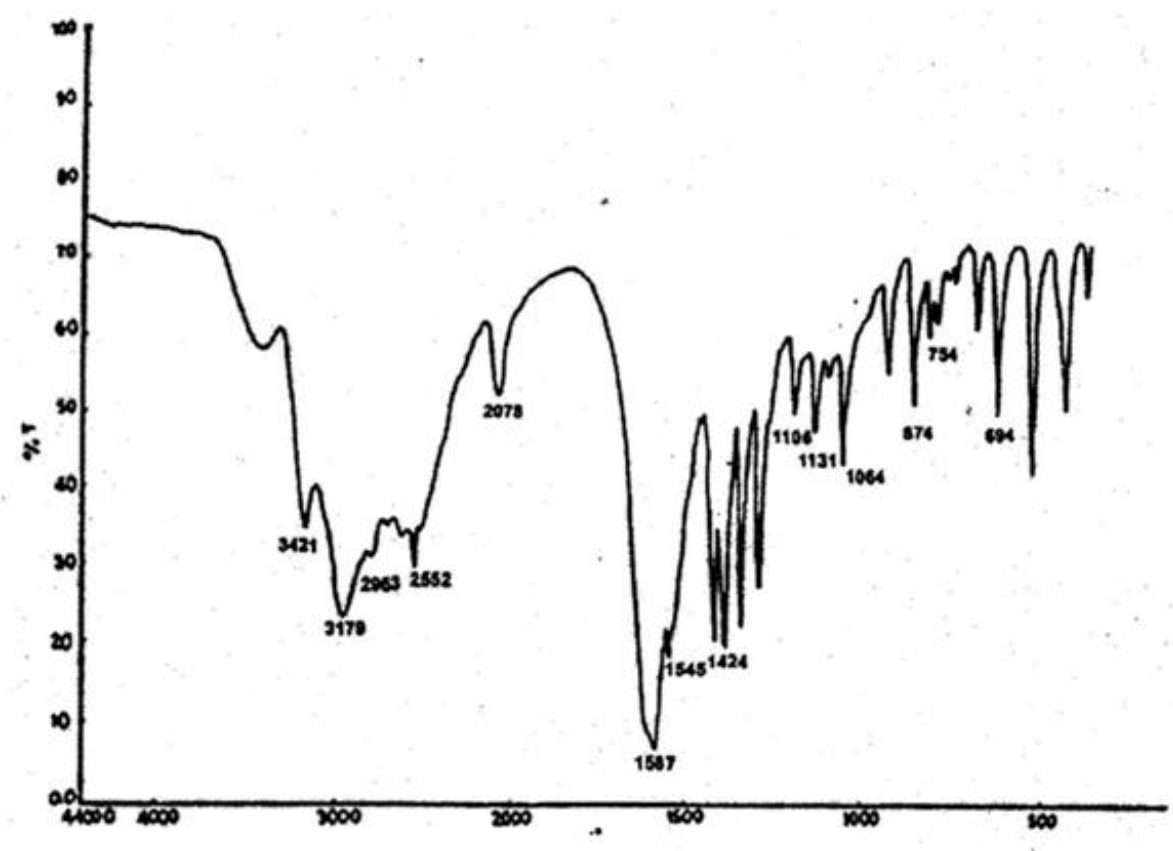

wavenumbers $\left(\mathrm{cm}^{-1}\right)$

Figure- 1(a) FTIR spectra of the substrate cysteine 


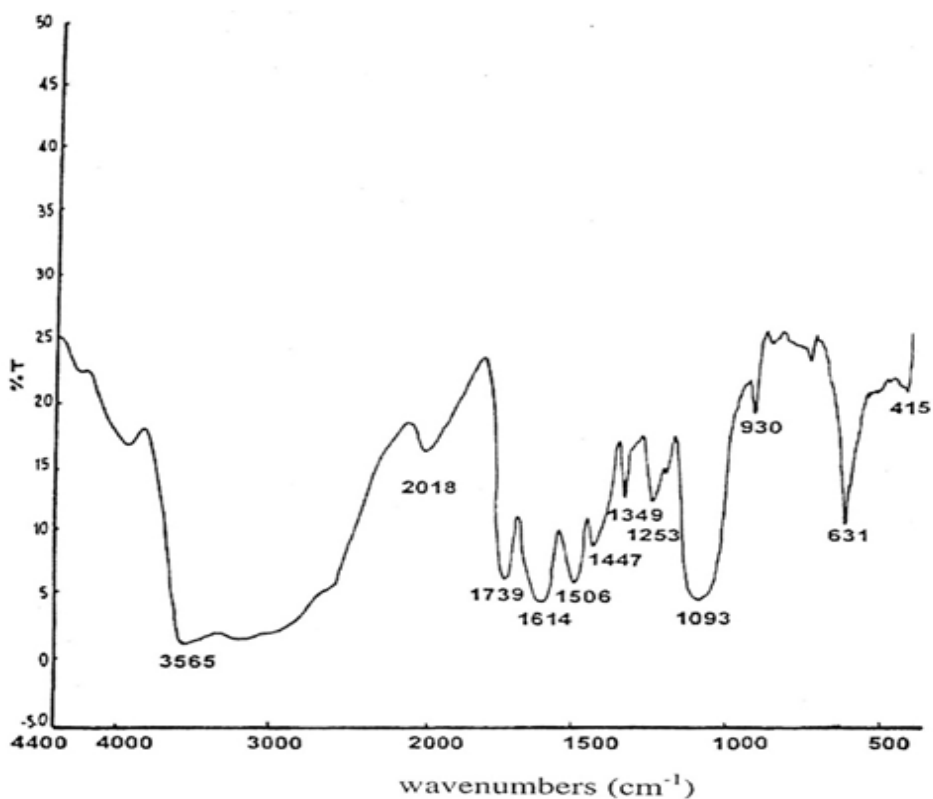

Figure 1(b)FTIR spectra of the product cystine

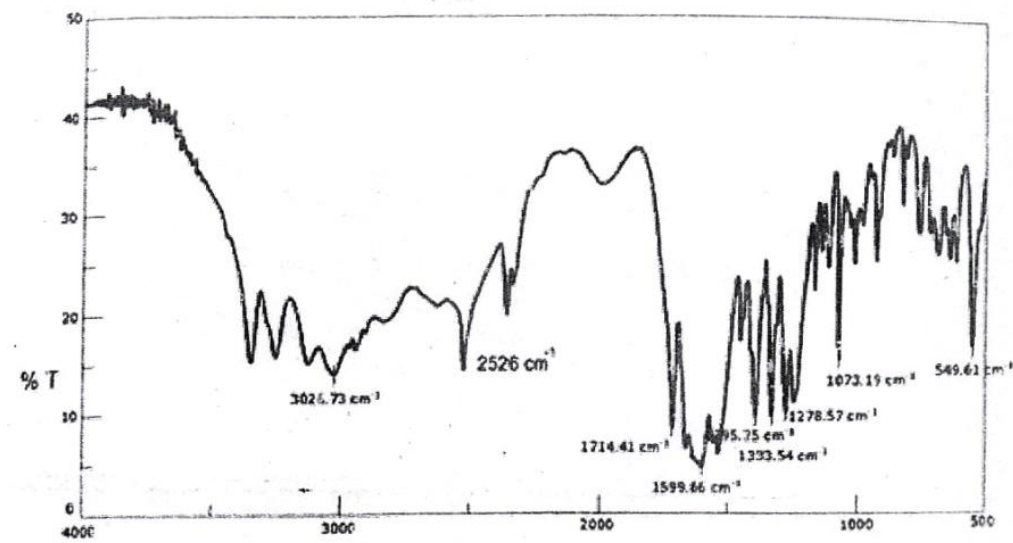

Wave number $\left(\mathrm{cm}^{-1}\right)$

Figure 1(c) FTIR spectra of pure GSH

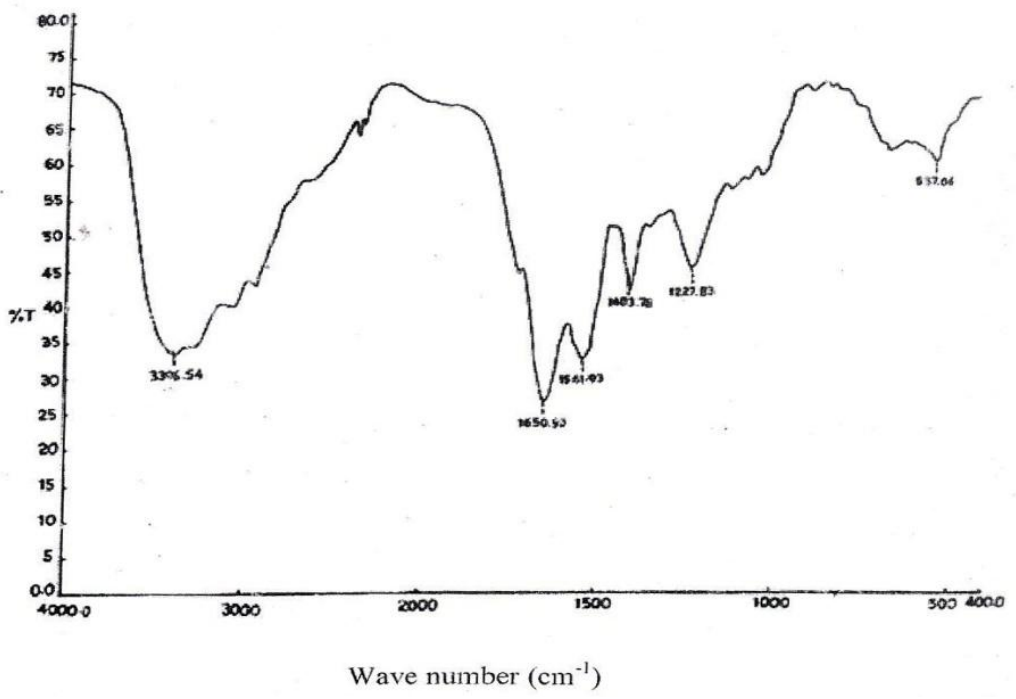

Figure 1(d) FTIR spectra of oxidation product GSSG 


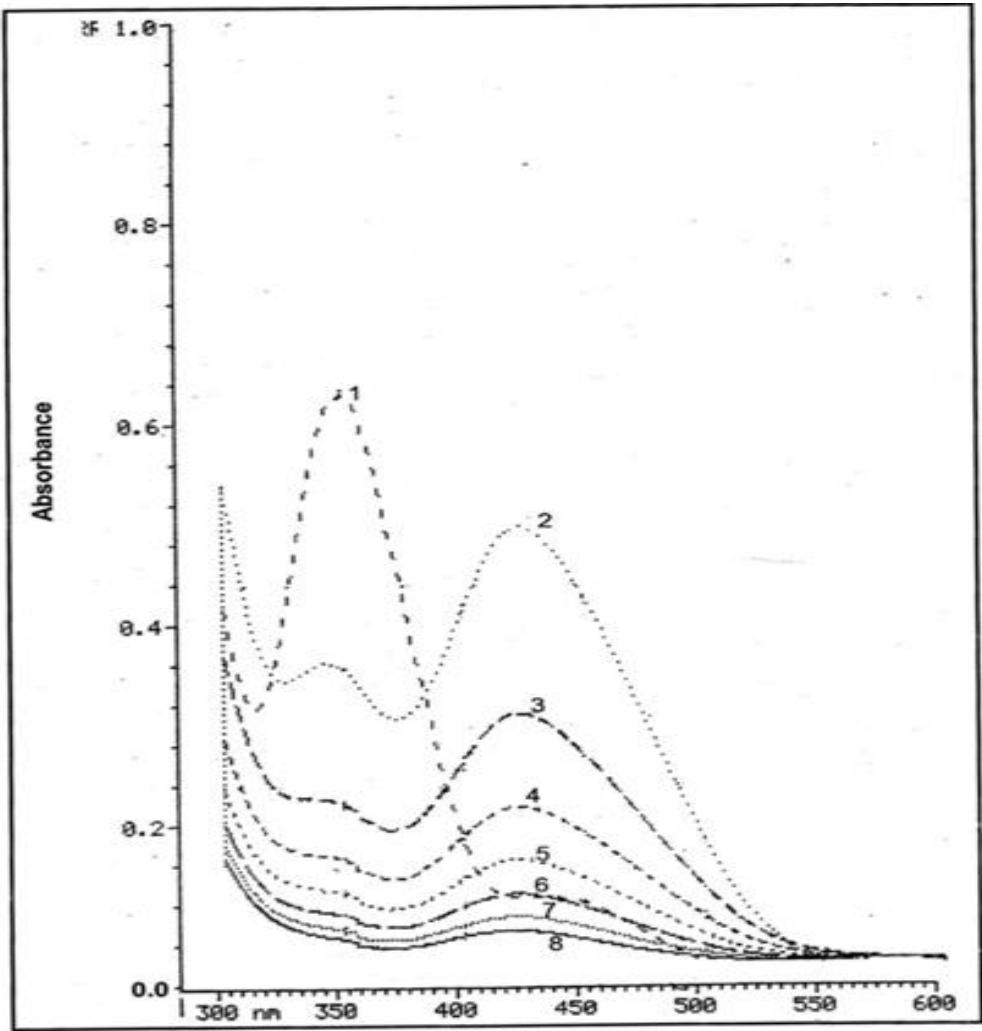

Wave Lengh ( $\mathrm{nm}$ )

Figure-2(a)UV-vistime Scan of Pipcc and L-cysteine mixture.

(1)

$[$ Pipcc $]=4.6 \times 10^{-4} \mathrm{~mol} \mathrm{dm}^{-3},\left[\mathrm{H}^{+}\right]=0.11 \mathrm{~mol} \mathrm{dm}^{-3}, \mathrm{I}=0.3 \mathrm{~mol} \mathrm{dm}^{-3}$ [cysteine] $=2.4 \times 10^{-3} \mathrm{~mol} \mathrm{dm}^{-3}$

Curves $(2-8), \Delta \mathrm{t}=10 \mathrm{~min}, 30^{\circ} \mathrm{C}$

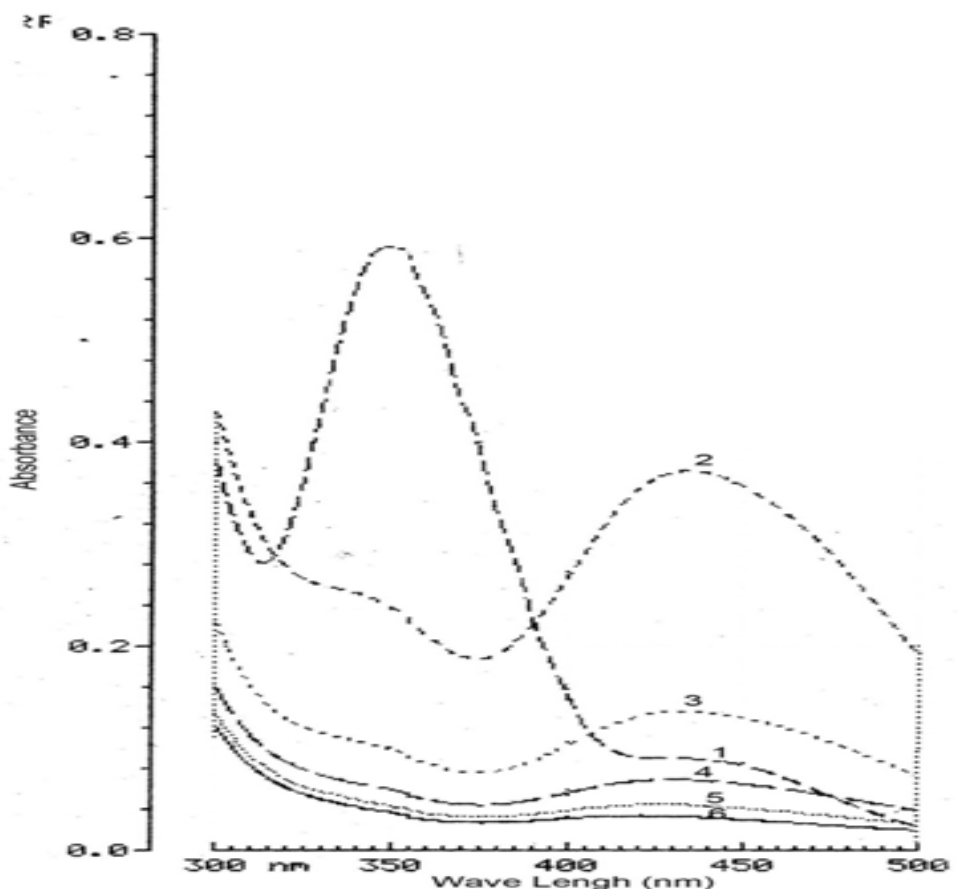

Figure-2(b)UV- Vis time scan of Pipcc and GSH mixture.

(1) $[\mathrm{Pipcc}]_{\mathrm{T}}=4.6 \times 10^{-4} \mathrm{~mol} \mathrm{dm}^{-3}, \mathrm{I}=0.3 \mathrm{~mol} \mathrm{dm}{ }^{-3},[\mathrm{GSH}]=4.6 \times 10^{-3} \mathrm{~mol} \mathrm{dm}^{-3}$ $\left[\mathrm{H}^{+}\right]=0.01 \mathrm{~mol} \mathrm{dm}^{-3}$, temp $=30^{0} \mathrm{C}, \lambda=300-500 \mathrm{~nm}$, at different time intervals Curve (2-6), $\Delta \mathrm{t}=15 \mathrm{~min}$ 


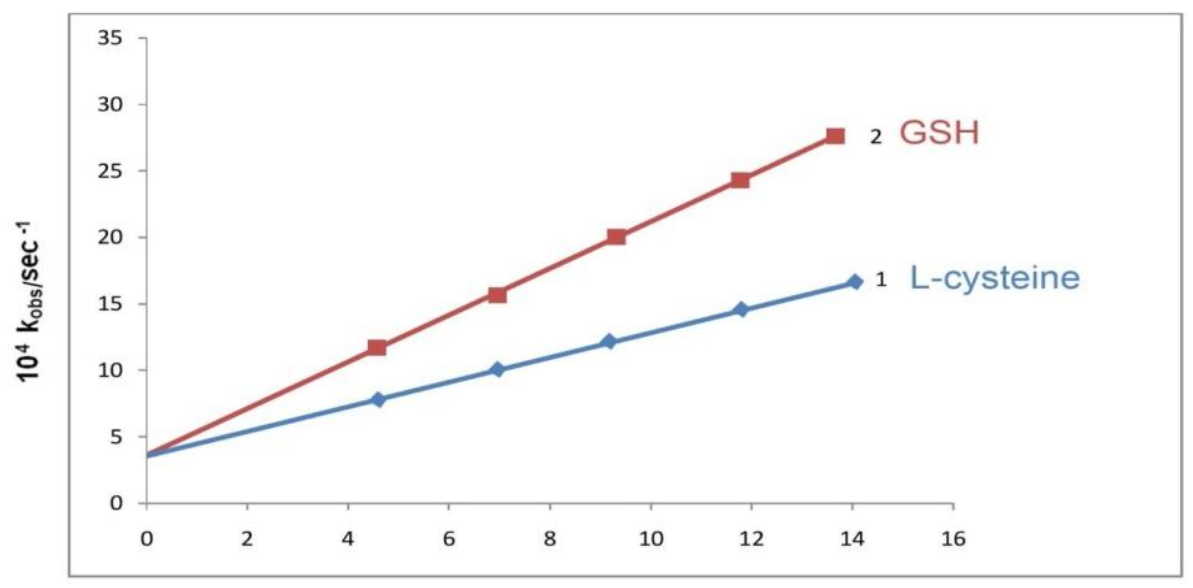

$10^{3}\left[\right.$ substrate] / $\mathrm{mol} \mathrm{dm}^{-3}$

Figure - 3The Plot of $10^{3}$ [substrate] $\left(\mathrm{mol} \mathrm{dm}^{-3}\right)$ vs $10^{4} \mathrm{k}_{\mathrm{obs}}\left(\mathrm{sec}^{-1}\right)$

Substrate may be L-cysteine or GSH

$[\text { Pipcc }]_{\mathrm{T}}=4.6 \times 10^{-4} \mathrm{~mol} \mathrm{dm}^{-3}$

$\left[\mathrm{H}^{+}\right]=0.01 \mathrm{~mol} \mathrm{dm}^{-3}, 30^{0} \mathrm{C}$

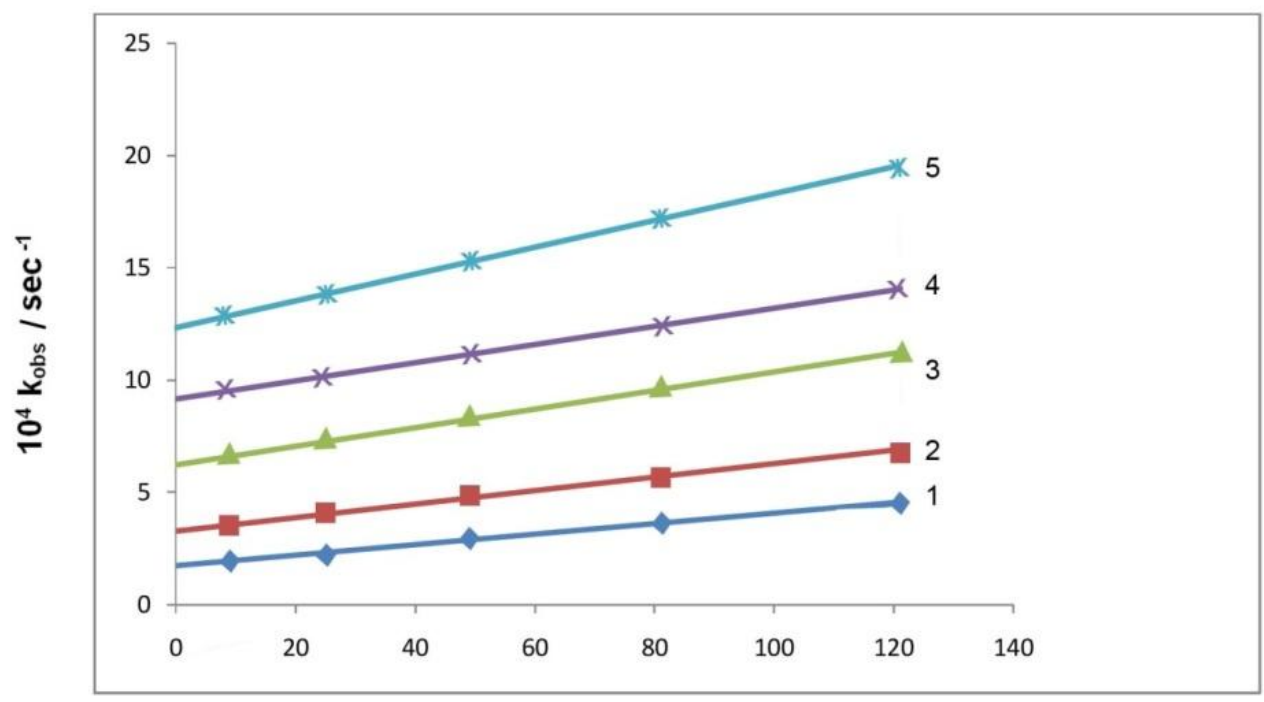

$10^{4}\left[\mathrm{H}^{+}\right]^{2} / \mathrm{mol}^{2} \mathrm{dm}^{-6}$

Fugure-4 The plot of $10^{4}\left[\mathrm{H}^{+}\right]^{2} / \mathrm{mol}^{2} \mathrm{dm}^{-6} / \mathrm{vs} 10^{4} \mathrm{k}_{\text {obs }} / \mathrm{sec}^{-1}$

(For Cysteine)

$[\text { Pipcc }]_{\mathrm{T}}=4.6 \times 10^{-4} \mathrm{~mol} \mathrm{dm}^{-3}$

[Cysteine $]=2.4 \times 10^{-3} \mathrm{~mol} \mathrm{dm}^{-3}$

$\mathrm{I}=0.3 \mathrm{~mol} \mathrm{dm}^{-3}$

At different temprature, (1) $20^{\circ} \mathrm{C}$, (2) $25^{\circ} \mathrm{C}$, (3) $30^{\circ} \mathrm{C}$, (4) $35^{\circ} \mathrm{C}$, (5) $40^{\circ} \mathrm{C}$ 


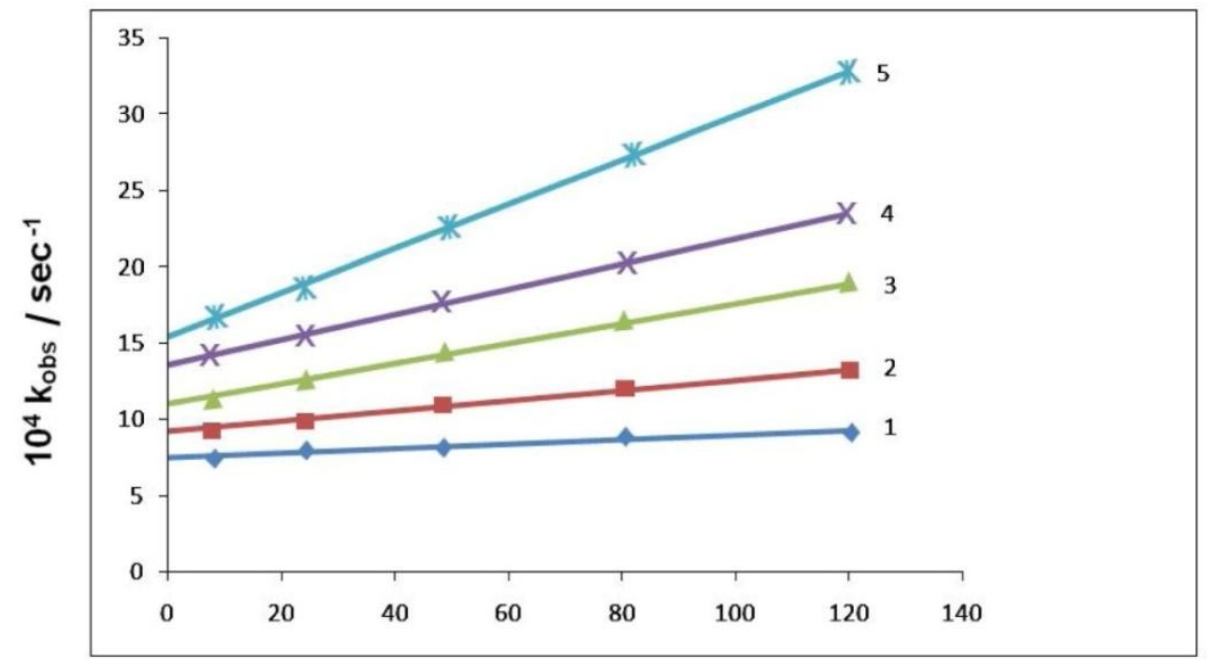

$10^{4}\left[\mathrm{H}^{+}\right]^{2} / \mathrm{mol}^{2} \mathrm{dm}^{-6}$

Figure -5 The Plot of $10^{4}\left[\mathrm{H}^{+}\right]^{2} / \mathrm{mol}^{2} \mathrm{dm}^{-6}$ vs $10^{4} \mathrm{k}_{\mathrm{obs}} / \mathrm{sec}^{-1}$

(For GSH)

$[\text { Pipcc }]_{\mathrm{T}}=4.6 \times 10^{-4} \mathrm{~mol} \mathrm{dm}^{-3}$

$[\mathrm{GSH}]=2.4 \times 10^{-3} \mathrm{~mol} \mathrm{dm}^{-3}$

$$
\mathrm{I}=0.3 \mathrm{~mol} \mathrm{dm}^{-3}
$$

At different temprature, (1) $20^{\circ} \mathrm{C}$, (2) $25^{\circ} \mathrm{C}$, (3) $30^{\circ} \mathrm{C}$, (4) $35^{\circ} \mathrm{C}$, (5) $40^{\circ} \mathrm{C}$

\section{Conclusion}

The kinetics of oxidation of GSH and L-Cysteine by piperidinium chlorochromate has been studied in acid medium. The rate of redox reaction was increased with increase in concentration of [substrate] and $\left[\mathrm{H}^{+}\right]$in both cases. The reaction follows first order in [substrate] and $\left[\mathrm{H}^{+}\right]$. The redox reaction involves two steps. One is acid independent path and other is acid dependent path. The reaction follows free redical mechanism. The isolated products of the redox reactions are cystine due to isomerisation of substrate cysteine and GSSG due to isomerisation of substrate GSH. Moderate values of activation parameters favour the electron transfer reaction.

\section{Acknowledgement}

One of the author is thankful to HOD Chemistry, Department of Chemistry, Utkal University for providing necessary facilities in the department and also thankful to Principal, Dhamnagar College, Dhamnagar for allowing him to complete his Ph.D. work.

[1]. EJ. Corey, J.W. Suggs, Tetrahedron Lett, 2647(1975)

\section{Reference}

[2]. F.S. Guzice Jr., F.A. Luzio, Org. Chem., 47, (1982), 1787, M. Tajbakhsh, R. Hosseinzadeh, M.Y. Niaki, J. Chem. Res (s), 508(2002).

[3]. K. Balasubramanian, V. Prathiba, Indian J. Chem., 25B, (2002)326; V.Murugesen, A. Pandurangan, Indian J. Chem., 31B5 (1992) 377; G.A. Rajkumar; B. Arabindoo, V. Murugesen, Synth.Commun.,29, 2105(1999).

[4]. S. Agrawal, H.P. Tiwari, J.P. Sharma, Tetrahedron, 46,1963(1990).

[5]. Pvamaiah, P.K. Dubey. J. Renianathan, C. Ravikumar, J.S. Grosser!, Indian J. Chem., 426,1765(2003).

[6]. Shirini, I.M. Baltrok, Z. Hezari, P. Heravi, Bull Korean Chem. Soc., 24, 517 (2003).

[7]. Roldan, A. Gonzalez, C. Palomo, Carbohydrate Res,,149, 1(1986).

[8]. Mamaghani, F. Shirini, F. Parsa, Russian J, Org. Chem., 38, 1113(2002).

[9]. Movassagh, M.M. Lakouraj, K. Ghodrati, Indian J. Chem., 41B, 1293(2002).

[10]. H.N. Sheikh, Madhu Sharma and B.L. Kalsotra, J. Indian Chem. Soc., 82, 913(2005).

[11]. A.I. Vogel, Text Book of Quantitative Chemical Analysis (5th ei), ELBS, Longman group UK (1989).

[12]. R.K. Dhar, Indian J. Chem., 31 A, 97 (1992).

[13]. V Sharma, P.K. Sharma and K.K. Banerji, J. Indian Chem. Soc., 74, 607 (1997).

[14]. S.A. Chimatadar, M.S. Salunke and S.T. Nandibewoor, J. Indian Chem. Soc., 83, 1093 (2006).

[15]. D. Malarvili, M. Pandeeswaran, D.S. Bhuvaneswari and K.P. Elango, J. Indian Chem. Soc., 83, 895(2006).

[16]. M. Balakrishnan, S. Ghammami and K.P. Elango, J. Indian Chem. Soc.,83, 497 (2006).

[17]. R. Kumbhat and V. Sharma, J. Indian Chem. Soc., 81, 745 (2004).

[18]. D. Yajurvedi, S. Kumbhani, I. Shastri, M. Baghmarand P.K. Sharma, J.Indian Chem. Soc., 85, 459 (2008).

[19]. S. Patel and B.K. Misra, Int. J. Chem. Kinet, 38, 1 (2006).

[20]. C. Karunakaran and S. Suresh, Int. J. Chem. Kinet, 37, 5 (2005). 